\title{
Criptógamos do Parque Estadual das Fontes do Ipiranga, São Paulo, SP. Algas, 38: Chlorophyceae (Tetrasporales e Siphonocladales)
}

\author{
Carlos Eduardo de Mattos Bicudo ${ }^{1,2}$
}

Recebido: 19.08.2013; aceito: 27.01.2014

\begin{abstract}
Cryptogams of the Parque Estadual das Fontes do Ipiranga, São Paulo, SP. Algae 38: Chlorophyceae (Tetrasporales and Siphonocladales)). Taxonomic survey of the Tetrasporales and Siphonocladales occurring in the ecosystems of Parque Estadual das Fontes do Ipiranga. Two genera of Tetrasporales (Tetrasporaceae, Chaetopeltis and Tetraspora), and three of Siphonocladales (Cladophoraceae, Cladophora, Pithophora and Rhizoclonium) were identified, each with a single species. Ninféias Pond was the system with the highest species richness, including representatives of all species presently identified, except for Tetraspora cylindrica. The hydrophytoterium had specimens of Tetraspora cylindrica, Pithophora roettleri and Rhizoclonium hieroglyphicum.
\end{abstract}

Keywords: Brazil, Chlorophyceae, floristic survey

RESUMO - (Criptógamos do Parque Estadual das Fontes do Ipiranga, São Paulo, SP. Algas 38: Chlorophyceae (Tetrasporales e Siphonocladales)). Levantamento das Tetrasporales e Siphonocladales que ocorrem nos ambientes aquáticos do Parque Estadual das Fontes do Ipiranga. Foram identificados dois gêneros (Tetrasporaceae, Chaetopeltis e Tetraspora) de Tetrasporales (Tetrasporaceae) com uma espécie de cada um e três gêneros (Cladophoraceae, Cladophora, Pithophora e Rhizoclonium) de Siphonocladales (Cladophoraceae), todos com apenas uma espécie. O Lago das Ninféias foi o ambiente que apresentou a maior riqueza de espécies, incluindo todas as presentemente identificadas, exceto Tetraspora cylindrica. O hidrofitotério apresentou representantes de Tetraspora cylindrica, Pithophora roettleri e Rhizoclonium hieroglyphicum.

Palavras-chave: Brasil, Chlorophyceae, levantamento florístico

\section{Introdução}

Vários trabalhos foram publicados a partir do estudo das microalgas planctônicas e perifíticas do Parque Estadual das Fontes do Ipiranga (PEFI). Entretanto, apenas os de Bicudo \& Bicudo (1970) e Bicudo (1996) fizeram referência à ocorrência de representante de Tetrasporales ao citarem Chaetopeltis minor Möbius para o Lago das Ninféias.

Bicudo \& Bicudo (1970) é uma chave para a identificação taxonômica dos gêneros de algas de águas continentais do Brasil. Os materiais de Tetrasporales e Siphonocladales abrangidos nessa chave apresentam descrição muito breve, porém, incluem ilustração que permitem, na maioria dos casos, a identificação da espécie. Entretanto, tais materiais não foram preservados. Bicudo (1996) é parte de um inventário criterioso das algas epífitas do Lago das Ninféias, contendo descrições detalhadas, farta ilustração e comentários importantes sobre cada espécie identificada. Este material faz parte do acervo do Herbário Científico do Estado "Maria Eneyda P. Kauffmann Fidalgo" (SP).

Os objetivos da presente contribuição foram os mesmos que nortearam a flora ficológica do PEFI e são: 1) realizar o levantamento taxonômico dos gêneros e espécies classificados nas famílias Tetrasporaceae e Cladophoraceae, isto é, as únicas de suas respectivas ordens, Tetrasporales e Siphonocladales (Chlorophyceae) que ocorrem no PEFI; e 2) apresentar descrições e ilustrações dos materiais identificados verificando novas ocorrências para o PEFI.

\section{Material e métodos}

O inventário foi baseado em coletas de material perifítico realizadas em pequenas represas localmente

1. Instituto de Botânica, Caixa Postal 68041, 04045-972 São Paulo, SP, Brasil

2. Autor para correspondência: cbicudo@terra.com.br 
chamadas lagos (Lago do IAG, Lago das Garças, Lago das Ninféias, Lago dos Bambus) e no hidrofitotério. O material foi coletado manualmente, por meio de espremidos de plantas submersas ou partes submersas de plantas emergentes. Também foi providenciada a coleta por meio de raspagens de exemplares inteiros ou de partes submersas de plantas aquáticas e daquele sobre pedras, além do que habita a camada superficial do sedimento.

A espécie constante da literatura, mas que não foi atualmente reencontrada teve seu nome citado na chave de identificação e no texto antecedido por um asterisco.

O sistema de classificação utilizado para gêneros e espécies de Tetrasporales e Siphonocladales foi de Bourrelly (1985). A sequência dos gêneros dentro de cada família e das espécies dentro de cada gênero seguiu a ordem alfabética.

Parte do material estudado encontra-se depositado em SP. Um número de espécimes estudados proveio do plâncton e as amostragens foram efetuadas nos 10 primeiros anos de coleta no PEFI. Nesta época, era ainda incipiente a preocupação de preservar todas as amostras coletadas, razão pela qual várias espécies ora identificadas não possuem material testemunho depositado no herbário institucional.

\section{Resultados e Discussão}

Foram identificados dois gêneros pertencentes à ordem Tetrasporales e três à Siphonocladales.

Os cinco gêneros presentemente identificados possuem a seguinte situação sistemática:

\section{Classe Chlorophyceae \\ Ordem Tetrasporales \\ Família Tetrasporaceae \\ Chaetopeltis \\ Tetraspora \\ Ordem Siphonocladales \\ Família Cladophoraceae \\ Cladophora \\ Pithophora \\ Rhizoclonium}

\section{TETRASPORALES}

\section{TETRASPORACEAE}

A principal característica dos representantes desta família são os pseudoflagelos, também chamados flagelos mucilaginosos ou pseudocílios, que estão situados na parte anterior da célula. As células podem ser solitárias (Porochloris) ou reunidas em colônias usualmente mucilaginosas. Nos dois casos, são imóveis na fase vegetativa. Os pseudoflagelos variam em número de 2, 4 ou 16 e são totalmente imóveis. $O$ cloroplastídio é único por célula, em geral urceolado, raro estrelado e possui um pirenoide localizado próximo ao centro do plastídio. A reprodução é vegetativa e origina 2, 4 ou 8 células-filhas usualmente reunidas em tétrades. Quando assexuada, os zoósporos possuem 2 ou 4 flagelos iguais. A reprodução sexuada ocorre pela fusão de isogametas biflagelados.

\section{Chave para identificação dos gêneros de Tetrasporaceae}

1. Colônias com forma definida, discoides, destituídas de mucilagem; pseudoflagelos livres ........................................... Chaetopeltis

1. Colônias sem forma definida, ricas em mucilagem; pseudoflagelos imersos na mucilagem colonial .... Tetraspora

\section{Chaetopeltis Berthold}

As formas adultas são discoides, mas também podem ser irregularmente lobadas e vivem epífitas, porém, sem estrutura de fixação ao hospedeiro. $\mathrm{O}$ disco é monostromático e formado por filamentos que irradiam de um centro comum. As células originalmente abauladas em seu lado livre tornam-se achatadas pela compressão mútua aparecendo angulosas. Cada célula tem um número de pseudoflagelos longos e eretos, os quais aparecem ao microscópio como cerdas longas e delicadas. O cloroplastídio é único em cada célula, urceolado e tem um pirenoide central.

Apenas uma espécie identificada:

Chaetopeltis minor Möbius, Berichte der Deutsche Botanische Gesellschafte 6: 247, pl. 12, fig. 1-20. 1888.

Figuras 1-5

Talo prostrado, discoide a irregularmente lobado, monostromático; bainha de mucilagem conspícua a pouco evidente, 150-200 $\mu \mathrm{m}$ diâm.; células organizadas em séries radiais ou quase, unidas lateralmente, usualmente sub-retangulares, célula central 7,5-14,6 $\mu \mathrm{m}$ compr., 5,9-9,9 $\mu \mathrm{m}$ larg., célula mediana 5,9-18,2 $\mu \mathrm{m}$ compr., 5,6-12,9 $\mu \mathrm{m}$ larg., célula marginal 8,1-23,4 $\mu \mathrm{m}$ compr., 8-12,8 $\mu \mathrm{m}$ 
larg.; cloroplastídio 1, parietal, laminar, pirenoide 1; pseudoflagelos 2 , em algumas células.

Hábitat: perifíton.

Material examinado: BRASIL. São PaUlo: São Paulo, Parque Estadual das Fontes do Ipiranga, Jardim Botânico de São Paulo, Lago das Ninféias, sobre Salvinia herzogii de la Sota, 30-I-1981, D.C. Bicudo s.n. (SP176807); 27-II-1981, D.C. Bicudo s.n. (SP176801); 31-III-1981, D.C. Bicudo s.n. (SP176816); 30-V-1981, D.C. Bicudo s.n. (SP176840); 31-III-1982, D.C. Bicudo s.n. (SP176964); sobre Valisneria spiralis L., 30-IV-1981, D.C. Bicudo s.n. (SP176828, SP176830); 30-VI-1981, D.C.
Bicudo s.n. (SP176859); 31-VII-1981, D.C. Bicudo s.n. (SP177026); 31-III-1982, D.C. Bicudo s.n. (SP176964); sobre Nymphaea elegans Hook., 31-III-1982, D.C. Bicudo s.n.(SP176964).

Distribuição no PEFI: Lago das Ninféias (Bicudo 1996).

Os representantes desta espécie podem ser confundidos com os de Chaetopeltis orbicularis Berthold, mas diferem por apresentar gametas biflagelados e talo com dimensões menores. Chaetopeltis orbicularis apresenta reprodução por zoósporos tetraflagelados e talo com cerca de $1.000 \mu \mathrm{m}$ de diâmetro. As dimensões do talo

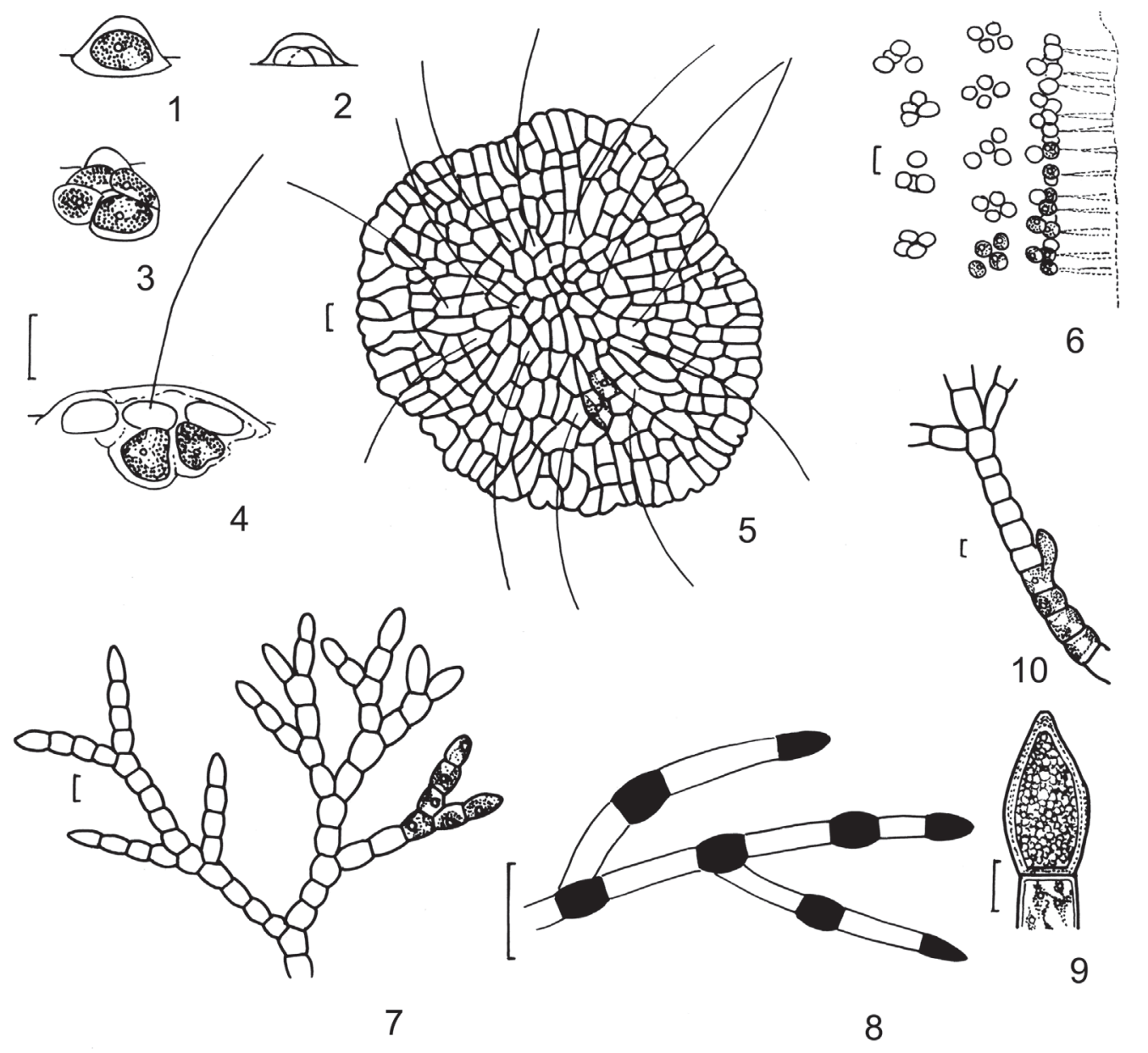

Figuras 1-10. Tetrasporales e Siphonocladales do Parque Estadual das Fontes do Ipiranga, São Paulo, SP, Brasil. 1-5. Chaetopeltis minor (de Bicudo 1996) 6. Tetraspora cylindrica (de Bicudo \& Bicudo 1970). 7. Cladophora glomerata (de Bicudo \& Bicudo 1970). 8-9. Pithophora roettleri (de Bicudo \& Bicudo 1970). 10. Rhizoclonium hieroglyphicum (de Bicudo \& Bicudo 1970). Escala das barras $=10 \mu \mathrm{m}$.

Figures 1-10. Tetrasporales and Siphonocladales of the Parque Estadual das Fontes do Ipiranga, São Paulo, São Paulo State, Brazil. 1-5. Chaetopeltis minor (from Bicudo 1996). 6. Tetraspora cylindrica (from Bicudo \& Bicudo 1970). 7. Cladophora glomerata (from Bicudo \& Bicudo 1970). 8-9. Pithophora roettleri (from Bicudo \& Bicudo 1970). 10. Rhizoclonium hieroglyphicum (from Bicudo \& Bicudo 1970). Scale bars $=10 \mu \mathrm{m}$. 
dependem, entretanto, da disponibilidade de nutrientes no ambiente (Heering 1914, Koršikov 1935, Printz 1964) e Huber (1892) observou espécimes cujas dimensões coincidiram com as de C. minor, mas, que em cultivo produziram zoósporos tetraflagelados como os de C. orbicularis. Conforme Huber (1892) e Ettl \& Gärtner (1988), há possibilidade de C. minor e C. orbicularis serem coespecíficas e da reprodução na então única espécie ser por gametas biflagelados e zoósporos tetraflagelados. Neste caso, C. minor seria sinônimo heterotípico de $C$. orbicularis.

\section{Tetraspora Link}

Indivíduos coloniais, de coloração verde-pálida e forma de saco cilíndrico, balão ou até bastante irregulares, porém, sempre visíveis a olho nu, podendo alcançar até cerca de $10 \mathrm{~cm}$ de diâmetro. As células são esféricas e distribuem-se, geralmente, aos pares ou em grupos de quatro na periferia de um envoltório mucilaginoso extremamente abundante. A distribuição dos grupos de células no interior da massa mucilaginosa é devida ao acaso. Cada célula possui dois pseudoflagelos que se estendem muito pouco além do envoltório de mucilagem. O cloroplastídio é único por célula, tem forma de urna (urceolado) e possui apenas um pirenoide. Dois vacúolos contráteis estão presentes próximos à base dos pseudoflagelos em cada célula.

Tetraspora possui sete ou oito espécies (Bourrelly 1985) já descritas, que vivem em águas frias e correntes de várias partes do mundo. $\mathrm{Na}$ área do PEFI, T. cylindrica (Wahlenberg) C. Agardh, a única espécie do gênero até hoje conhecida para a área, só foi coletada durante o inverno e no hidrofitotério, onde a água possui pouca correnteza.

Apenas uma espécie identificada:

Tetraspora cylindrica (Wahlenberg) C. Agardh, Systema algarum 1: 188. 1824 E Ulva cylindrica Wahlenberg, Flora Lapponiae. 509, pl. 30, fig. 1. 1812.

Figura 6

Talo cilíndrico, irregularmente lobado, fixo quando jovem, depois livre-flutuantes, constituído por mucilagem firme, que pode atingir até $50 \mathrm{~cm}$ de comprimento, afilado na extremidade de fixação; células esféricas, quando jovens em grupos de 4 irregularmente distribuídos na mucilagem colonial, 13-15,5 $\mu \mathrm{m}$ diâm.; cloroplastídio único, 1 pirenoide.

Hábitat: plâncton.
Material examinado: BRASIL. São PAULo: São Paulo, hidrofitotério, material não preservado.

Distribuição no PEFI: hidrofitotério.

Tetraspora cylindrica (Wahlenberg) C. Agardh é uma espécie única por formar tubos mucilaginosos ocos, mais ou menos irregulares, que lembram intestino e vivem fixos a um substrato durante toda sua existência. As demais espécies do gênero formam primeiro tubos mucilaginosos, mas logo se expandem formando estruturas globosas ou laminares.

\section{SIPHONOCLADALES}

\section{CLADOPHORACEAE}

Indivíduos filamentosos simples ou ramificados e, às vezes, formando um talo discoide pluriestratificado. As células são sempre multinucleadas e possuem um cloroplastídio parietal reticulado com numerosos pirenoides ou, mais raramente, vários plastídios discoides com um pirenoide cada um (Chaetonella possui plastídios parietais discoides, mas destituídos de pirenoide). A multiplicação assexuada ocorre por zoósporos tetraflagelados de tamanhos iguais entre si, mas também por aplanósporos ou acinetos. A reprodução sexuada se faz por isogamia ou anisogamia, onde os gametas são biflagelados.

A ordem Siphonocladales é predominantemente de águas marinhas e todos os seus representantes que habitam as águas continentais pertencem a esta família: Cladophoraceae.

\section{Chave para identificação dos gêneros de Cladophoraceae}

1. Filamentos com poucas ou destituído de ramificações . Rhizoclonium

1. Filamentos com numerosas ramificações

2. Acinetos sempre presentes Pithophora

2. Acinetos ausentes Cladophora

\section{Cladophora Kützing}

Algas macroscópicas que vivem, quando jovens, presas a um substrato por um apressório discoide e/ ou projeções rizoidais livres e, quando mais velhas, flutuando na água. $\mathrm{O}$ talo consiste de filamentos unisseriados, esparsa ou profusamente ramificados. As ramificações são dicotômicas ou quase, e têm origem logo abaixo dos septos transversais. As células podem ser cilíndricas ou ter a forma aproximada de barril (doliformes); são usualmente longas e possuem a parede em geral bastante espessa e lamelada. $\mathrm{O}$ 
cloroplastídio é único por célula, ocupa posição parietal, é reticulado e possui numerosos pirenoides.

Os representantes de Cladophora são dominantemente marinhos, mas C. glomerata é muito comum nas águas doces do mundo inteiro, sendo abundantes em ambientes eutróficos, cujo teor de metais pesados seja baixo no sistema. A identificação das espécies deste gênero não é fácil, pois elas exibem acentuada variação morfológica dependendo das condições ambientais, o que torna discutível e até mesmo duvidosa a identificação taxonômica de vários materiais. Além do polimorfismo, existe considerável recobrimento entre as características utilizadas na separação de várias espécies, o que torna ainda mais problemático o processo de sua identificação.

Apenas uma espécie identificada:

Cladophora glomerata (Linnaeus) Kützing, Phycologia generalis. 1843 E Conferva glomerata Linnaeus, Species plantarum. 1167. 1753. Figura 7

Filamentos profusa ou esparsamente ramificados, crescimento apical exceto nas plantas livre-flutuantes, onde as divisões celulares são intercalares, ocorrendo a certa distância do ápice; ramificação pseudodicótoma, ramos laterais formados na porção superior do eixo principal; células cilíndricas, 1,3-2,3 vezes mais longas que largas, 13,3-23,4 $\mu \mathrm{m}$ compr., 3,5-4,5 $\mu \mathrm{m}$ larg.; cloroplastídio 1, laminar, parietal; pirenoides numerosos.

Hábitat: plâncton.

Material examinado: BRASIL. São PAULO: São Paulo, Lago das Ninféias (material não preservado).

Distribuição no PEFI: Lago das Ninféias.

Os poucos espécimes examinados ocorreram no plâncton e foram representados por plantas com ramificação profusa. As dimensões do comprimento e da largura celular são consideravelmente menores do que aquelas constantes na literatura (20-50 $\mu \mathrm{m}$ larg.), porém, a diferença da relação entre o comprimento e a largura da célula (3-6 vezes) não é tão significativa.

\section{Pithophora Wittrock}

Os espécimes são macroscópicos e vivem flutuando livremente na água. Os filamentos são unisseriados e livremente ramificados. A ramificação é em geral lateral, embora possa ser oposta em alguns casos. Os ramos são originados imediatamente abaixo dos septos transversais. Ramos rizoidais uni ou multicelulares podem se formar a partir da base de certos filamentos. As células são cilíndricas, em geral longas e possuem parede frequentemente espessa. O cloroplastídio é único, situa-se parietalmente na célula, é reticulado e possui numerosos pirenoides. A reprodução ocorre por acinetos, cuja forma de barril (doliforme) e parede bastante espessa é característica diagnóstica para identificação do gênero. Os acinetos podem se formar na extremidade dos filamentos ou ocorrer intercalarmente.

Apenas uma espécie identificada:

Pithophora roettleri (Roth) Wittrock, Nova Acta Regiae Societatis Scientiarum Upsaliensis: sér. 3, 19: 66. 1877 ECeramium roettleri Roth, Catalecta botânica quibus plantae novae et minus cognitae describuntur atque illustrantur 3: 123. 1913.

Figuras 8-9

Filamentos unisseriados, livremente ramificados, ramos curtos, 3-4-celulados; células cilíndricas, 4,7-12,3 $\mu \mathrm{m}$ compr., 2-2,9 $\mu \mathrm{m}$ larg., acinetos intercalares em forma de barril (doliformes), 2,4-2,9 $\mu \mathrm{m}$ compr., 3,5-4,1 $\mu \mathrm{m}$ larg., acinetos terminais cônicos, 4,7-10 $\mu \mathrm{m}$ compr., 1,8-2,6 $\mu \mathrm{m}$ larg.; cloroplastídio 1 , reticulado, numerosos pirenoides.

Hábitat: plâncton.

Material examinado: BRASIL. São PAULO: São Paulo, Lago das Ninféias e hidrofitotério.

Distribuição no PEFI: Lago das Ninféias e hidrofitotério (material não preservado).

Pithophora sumatrana (G. Martens) Wittrock é a única espécie conhecida até o momento para o Brasil e foi coletada apenas nas vizinhanças de Cuiabá, Estado de Mato Grosso (Schmidle 1901), cuja publicação nada mais contém além da citação do nome da espécie. Bicudo \& Bicudo (1970) documentaram a presença de P. oedogonia (Montagne) Wittrock no hidrofitotério do Jardim Botânico de São Paulo também, entretanto, sem descrever o material identificado, que não foi preservado. O nome $P$. oedogonia (Montagne) Wittrock é considerado sinônimo heterotípico de $P$. roettleri (Roth) Wittrock.

\section{Rhizoclonium Kützing}

Indivíduos macroscópicos que vivem, quando jovens, presos a algum substrato por projeções rizoidais livres e depois, mais velhos, flutuando livremente na água. Os filamentos são unisseriados e simples, mas também podem ser ramificados, embora raramente. Os 
ramos laterais são curtos e pouco numerosos. Ramos rizoidais igualmente curtos, constituídos por uma ou algumas poucas células podem ocorrer formando um ângulo reto com as células do eixo principal da alga. As células são cilíndricas, em geral duas a três vezes mais longas do que largas e possuem a parede espessa e lamelada. O cloroplastídio é único por célula, onde se situa parietalmente, é reticulado e possui numerosos pirenoides. A célula basal do filamento é alongada de modo a formar um rizoide de fixação que pode, às vezes, ser digitado. Formam-se, com frequência, rizoides secundários. A reprodução se faz por zoósporos biflagelados. A presença de acinetos foi observada neste gênero.

Apenas uma espécie identificada:

Rhizoclonium hieroglyphicum (C. Agardh) Kützing, Phycologia germanica. 206. $1845 \equiv$ Conferva hieroglyphica C. Agardh, Flora 10(40): 636. 1827. Figura 10

Filamentos unisseriados esparsamente ramificados, ramos laterais curtos, pouco numerosos, ramos rizoidais igualmente curtos, constituídos por 1 ou poucas células, formando ângulo reto com as células do eixo principal; células cilíndricas, 3,2-3,6 vezes mais longas que largas, 72,5-90,7 $\mu \mathrm{m}$ compr., 20-28,5 $\mu$ m diâm., parede espessa, lamelada; rizoides ausentes; cloroplastídio 1, parietal, nitidamente reticulado, numerosos pirenoides.

Hábitat: plâncton.

Material examinado: BRASIL. S̃̃o PAULO: São Paulo, Lago das Ninféias e hidrofitotério.

Distribuição no PEFI: Lago das Ninféias e hidrofitotério (material não preservado).

Todos os espécimes de $R$. hieroglyphicum (C. Agardh) Kützing coletados ocorreram no plâncton, razão pela qual não apresentaram rizoides. Pouco era conhecido sobre o histórico de vida desta espécie, mas Parodi \& Cáceres (1993) o descreveram em minúcias ao estudarem material coletado de várias localidades dos arredores de Bahia Blanca, na Argentina, que mantiveram em cultivo.

Chave para identificação dos gêneros e espécies das ordens Tetraporales e Siphonocladales do PEFI

1. Indivíduos com pseudoflagelos

2. Colônias discoides, destituídas de mucilagem; pseudoflagelos livres

2. Colônias sem forma definida, ricas em mucilagem; pseudoflagelos imersos na mucilagem colonial (Tetraspora) T. cylindrica

1. Indivíduos sem pseudoflagelos

3. Filamentos com poucas ou destituído de ramificações

3. Filamentos com numerosas ramificações

4. Acinetos sempre presentes

4. Acinetos ausentes

\section{Considerações finais}

Há uma pequena representatividade de exemplares das ordens Tetrasporales e Siphonocladales na área do PEFI, apesar de se haver coletado abundante material perifítico durante, principalmente, os 20 últimos anos.

A separação dos gêneros Rhizoclonium e Cladophora não é, por um lado, tão pronta, pois nem sempre se consegue definir a abundância de ramificações com precisão, apesar desta abundância ser o melhor critério para separar os dois gêneros. Isto é válido, mormente, quando se trabalha com plantas jovens. Por outro lado, é difícil identificar as espécies de Cladophora, pois elas exibem considerável polimorfismo devido às condições ambientais, um fato que torna discutíveis, segundo Bicudo \& Menezes (2006), e até bastante duvidosas as identificações taxonômicas de vários materiais.
(Pithophora) P. roettleri

(Rhizoclonium) R. hieroglyphicum (Cladophora) C.glomerata

O maior número de espécies foi identificado para o Lago das Ninféias, incluindo todas as presentemente inventariadas, exceto Tetraspora cylindrica. Esta espécie apenas ocorreu no hidrofitotério que apresentou, por sua vez, representantes de Tetraspora cylindrica, Pithophora roettleri e Rhizoclonium hieroglyphicum, mas não de Chaetopeltis minor e Cladophora glomerata. O hidrofitotério recebe águas do Lago dos Bugios e desagua no Lago das Ninféias. Trata-se, contudo, de um ambiente artificial construído com pequenos espaços onde se faz a exibição de macrófitas aquáticas, no qual a circulação da água é bastante limitada e seu confinamento facilitado.

\section{Agradecimentos}

O autor expressa seu melhor agradecimento ao CNPq, Conselho Nacional de Desenvolvimento 
Científico e Tecnológico, por bolsa de produtividade científica (processo $\mathrm{n}^{\circ} 309474 / 2010-8$ ).

\section{Literatura citada}

Bicudo, C.E.M. \& Bicudo, R.M.T. 1970. Algas de águas continentais brasileiras: chave ilustrada para identificação de gêneros. Fundação Brasileira para o Desenvolvimento do Ensino de Ciências, São Paulo.

Bicudo, C.E.M. \& Menezes, M. 2006. Gêneros de algas de águas continentais do Brasil: Chave para identificação e descrições. $2^{\mathrm{a}}$ ed. RiMa Editora, São Carlos.

Bicudo, D.C. 1996. Algas epífitas do Lago das Ninféias, São Paulo, Brasil, 4: Chlorophyceae, Oedogoniophyceae e Zygnemaphyceae. Revista Brasileira de Biologia 56: 345-374.

Bourrelly, P.C. 1985. Les algues d'eau douce: initiation à la systématique, 1: les algues vertes. Éditions N. Boubée \& Cie. ( $2^{\mathrm{a}}$ edição).
Ettl, H. \& Gärtner, G. 1988. Chlorophyta, 2: Tetrasporales, Chlorococcales, Gloeodendrales. In: Ettl, H., Gerloff, J., Heynig, H. \& Mollenhauer, D. (eds). Süßwasserflora von Mitteleuropa. Gustav Fischer Verlag, Stuttgart.

Heering, W. 1914. Ulothricales, Microsporales, Oedogoniales. In: Pascher, A. (ed.). Die SüsswasserFlora Deutschlands, Österreich und der Schweiz. vol. 3, part 6. Verlag Gustav Fischer, Jena.

Huber, M.J. 1892. Contributions à la connaissance des Chaetophorées épiphites et de leurs affinités. Annales des Sciences Naturelles: série 7, 16: 267-359.

Koršikov, A.A. 1935. On the taxonomical position of Chaetopeltis orbicularis: a preliminary report. Ucheni Zap Khanr'kyiv derzh Univ 1: 13-19.

Parodi, E.R. \& Cáceres, E.J. 1993. Life history of freshwater populations of Rhizoclonium hieroglyphicum (Cladophorales, Chlorophyta). European Journal of Phycology 28: 69-74.

Printz, H. 1964. Die Chaetophoralen der Binnengewässer: eine systematische Übersicht. Hydrobiologia 14: 1-376.

Schmidle, W. 1901. Algen aus Brasilien. Hedwigia 40(1): 45-54. 
